\title{
Determining stages of cirrus evolution: a cloud classification scheme
}

\author{
Benedikt Urbanek, Silke Groß, Andreas Schäfler, and Martin Wirth \\ Deutsches Zentrum für Luft- und Raumfahrt, Institut für Physik der Atmosphäre, Oberpfaffenhofen, Germany \\ Correspondence to: Benedikt Urbanek (benedikt.urbanek@dlr.de)
}

Received: 5 October 2016 - Discussion started: 24 October 2016

Revised: 3 March 2017 - Accepted: 2 April 2017 - Published: 3 May 2017

\begin{abstract}
Cirrus clouds impose high uncertainties on climate prediction, as knowledge on important processes is still incomplete. For instance it remains unclear how cloud microphysical and radiative properties change as the cirrus evolves. Recent studies classify cirrus clouds into categories including in situ, orographic, convective and liquid origin clouds and investigate their specific impact. Following this line, we present a novel scheme for the classification of cirrus clouds that addresses the need to determine specific stages of cirrus evolution. Our classification scheme is based on airborne Differential Absorption and High Spectral Resolution Lidar measurements of atmospheric water vapor, aerosol depolarization, and backscatter, together with model temperature fields and simplified parameterizations of freezing onset conditions. It identifies regions of supersaturation with respect to ice (ice-supersaturated regions, ISSRs), heterogeneous and homogeneous nucleation, depositional growth, and ice sublimation and sedimentation with high spatial resolution. Thus, all relevant stages of cirrus evolution can be classified and characterized. In a case study of a gravity leewave-influenced cirrus cloud, encountered during the MLCIRRUS flight campaign, the applicability of our classification is demonstrated. Revealing the structure of cirrus clouds, this valuable tool might help to examine the influence of evolution stages on the cloud's net radiative effect and to investigate the specific variability of optical and microphysical cloud properties in upcoming research.
\end{abstract}

\section{Introduction}

Cirrus play an important role for weather and climate: besides their influence on the water vapor budget in the upper troposphere through condensation and evaporation (Dinh et al., 2014) and dynamics due to latent heat (Spichtinger,
2014), they modify the radiation balance of the Earth and atmosphere. Thin, opaque cirrus clouds transmit most of the incident solar radiation and absorb long-wave radiation from the Earth's surface. As they are typically high and cold, they only emit little long-wave radiation into space, and thus cause a trapping of radiative energy in the Earth-atmosphere system, which eventually contribute to a rising surface temperature. If the cloud is thick, reflection of solar radiation back to space can become greater than the long-wave absorption, and consequently can cause the surface of the Earth to cool (Baran, 2009). This net radiative effect depends on macroscopic cloud properties like optical thickness, ice water content, and geometric extent as well as on its microphysical parameters such as ice crystal number, size, and shape (Schnaiter et al., 2016; Gallagher et al., 2012; Zhang et al., 1999).

Recent studies have investigated factors that affect these properties: the amount and composition of natural and anthropogenic aerosol particles in the troposphere and their ability to nucleate ice crystals are determining details of heterogeneous freezing (DeMott et al., 2010), but aerosol distribution and properties have not been well known until today, in particular in the temperature range of cirrus clouds. Exact freezing conditions and mechanisms were studied by Cziczo et al. (2013) from in situ measurements taken during flight campaigns conducted in Central and North America. They found a dominance of heterogeneous freezing with mineral dust and metallic particles as the main source of residual particles. Although they managed to span a range of geographic regions and seasons, it is not clear whether those results are globally valid.

High water vapor supersaturations inside and outside of cirrus clouds point to several microphysical processes and often occur together with low ice crystal numbers (Krämer et al., 2009). Sublimation of ice crystals was reported to re- 
sult in the disappearance of facets and corners, changing the crystal symmetry (Korolev and Isaac, 2006). The dependence of freezing on the updraft velocity during cloud formation is theoretically known (Kärcher and Lohmann, 2002), but measurements are difficult and rare. In idealized settings, there is also a good understanding of the relevant processes in cloud formation and break up. But in nature no two clouds are alike and there exists a confusing variability of conditions under which they occur. This makes it difficult to represent cirrus clouds adequately in global circulation models for weather and climate prediction (Baran, 2012; Zhang et al., 2005).

In order to gain more insight into the particular role of different cirrus clouds, great efforts were made to classify cirrus by the meteorological contexts in which they occur (Jackson et al., 2015; Muhlbauer et al., 2014). Categories include synoptic, orographic, lee wave and anvil cirrus. Recently a more general classification was introduced that distinguishes the groups of liquid origin and in situ clouds that describe whether the cirrus is formed by existing water droplets freezing at water saturation or by the freezing of solution droplets or heterogeneous nucleation at ice supersaturation but below water saturation (Krämer et al., 2016; Wernli et al., 2016). Such classifications of recorded data are a prerequisite for statistically investigating the specific properties and influences of different clouds and to extract the governing mechanisms and parameters from remote sensing and in situ measurements.

Likewise, detailed knowledge of cloud properties at different stages of evolution is yet to be gained, as a cloud is expected to show different properties at the time of formation and dissipation. During the evolution of a cloud ice particle number, effective radius and particle shape evolve as well. For instance, Korolev and Isaac (2006) showed that during dissipation, ice crystals lose single facets and corners, thus changing their geometry significantly. Besides such changes of microphysical properties, macrophysical qualities like the exact location, altitude and extent of cloud parts in a specific evolution state may also result in a different net radiative effect. A classification scheme that reveals the spatial distribution of evolution stages would facilitate the investigation of possible dependencies on cirrus evolution.

Heymsfield (1975) first illustrated and documented the vertical and dynamical structure of ice-generating cirrus uncinus clouds. This early work and following in situ measurements (Heymsfield and Miloshevich, 1995) indicate that there is a vertical order of cirrus evolution stages with ice nucleation near cloud top level, deposition of water vapor onto ice crystals and thus particle growth in the middle, and sublimation and sedimentation at cloud base level. A more recent, statistical study by Comstock et al. (2004) evaluated an extensive data set of ground-based lidar measurements taken at the ARM Southern Great Plains site (Oklahoma, USA) over a time period of 1 year. Vertical profiles of determined relative humidity with respect to ice $\left(\mathrm{RH}_{\mathrm{i}}\right)$ inside of cirrus clouds were divided into the upper most $25 \%$, the middle
$50 \%$, and the lower $25 \%$ of total cloud depth. The frequency distribution of $\mathrm{RH}_{\mathrm{i}}$ of the upper $25 \%$ shows a considerable amount of supersaturated regions with high $\mathrm{RH}_{\mathrm{i}}$ values up to $160 \%$, associated with ice nucleation. The distribution of the lower $25 \%$ is shifted towards subsaturation with a maximum between 70 and $80 \%$ and values down to $10 \%$, clearly dominated by crystal sedimentation and sublimation. Therefore they showed that the generally accepted vertical order of evolution stages dominated the majority of measured clouds while individual clouds, depending on cloud type, generation mechanism, cloud age, and atmospheric dynamics, may show strongly differing distributions (Comstock et al., 2004; Groß et al., 2014). The classification scheme that we present is based on atmospheric lidar cross sections and therefore facilitates the detailed investigation of evolution stages, their vertical and horizontal order, the impact of atmospheric dynamics, and their specific optical properties.

Such a classification needs information on $\mathrm{RH}_{\mathrm{i}}$ and temperature, as they are two governing variables in ice particle formation, growth, and disappearance (Pruppacher and Klett, 2010). In order for ice to form in the atmosphere, $\mathrm{RH}_{\mathrm{i}}$ must reach or surpass $100 \%$. It is well known that tropospheric air masses often show substantial supersaturations with respect to ice (Spichtinger et al., 2003). These so called ice-supersaturated regions (ISSRs) result mainly from upward motion of air masses originating in diverse atmospheric dynamics like large-scale synoptic ascent (e.g., warm conveyor belt), convective systems or mesoscale gravity waves (Spichtinger et al., 2005a, b; Field et al., 2001).

The existence of an ISSR does not automatically imply the existence or formation of a cirrus cloud. For the homogeneous freezing (HOM) of solution droplets at cirrus temperatures (typically below $235 \mathrm{~K}$ ), high supersaturations of the order of $140 \%$ are necessary (Koop et al., 2000). Additionally, solid aerosol particles can act as ice nuclei and thus lead to freezing under a much broader range of conditions. Heterogeneous freezing onset temperatures and saturation ratios depend strongly on aerosol type, coating of the particles and their size, and are still subject to current research (Hoose and Möhler, 2012).

Once ice particles are present and no cooling, for example from updraft motion, takes place, remaining supersaturation is quickly depleted by deposition of water vapor onto existing crystals. In updraft regions of ice clouds, however, it may take a few minutes to a few hours until the air reaches the quasi-steady supersaturation which is a function of vertical velocity and ice particle size distribution and higher than $100 \%$ for positive vertical velocities (Korolev and Mazin, 2003). Furthermore, effects that hinder phase relaxation are discussed, stemming from, for example, liquid coating around ice particles (Bogdan and Molina, 2009) or dynamic processes (Spichtinger and Krämer, 2013). Thus, supersaturation inside of ice clouds can persist for a substantial amount of time. Likewise, regions of subsaturation with respect to ice can emerge when heavy ice particles sediment 
out of the ISSR, or $\mathrm{RH}_{\mathrm{i}}$ is reduced by warming. These regions are dominated by sublimation of ice crystals (Korolev and Isaac, 2006; Kübbeler et al., 2011).

It can be seen that detailed knowledge of humidity and temperature in and around the cloud, as well as knowledge about freezing onset conditions is necessary in order to identify different stages of cloud evolution. The airborne Differential Absorption Lidar WALES (WAter vapour Lidar Experiment in Space), flown aboard the German research aircraft HALO (High Altitude and LOng range, model: Gulfstream G550), makes major parts of the needed data available. It provides an unique data set of collocated, high spatial resolution measurements of atmospheric backscatter, depolarization, and water vapor, enabling us to distinguish incloud and cloud-free regions, to identify the relevant aerosol type in the vicinity of the cloud, and to calculate relative humidity.

In this paper, we present a detailed classification scheme for the evolution of cirrus clouds. Besides WALES measurements we use complementary model temperature fields from the European Centre for Medium-range Weather Forecasts (ECMWF). Provided with high-resolution, two-dimensional lidar cross sections of the atmosphere, we are able to study the structure of clouds and the spatial distribution of classified evolution stages. By setting in situ and remote sensing data in perspective to cirrus evolution, it facilitates the study of the specific optical, microphysical, and radiative properties of evolution stages. We apply our scheme in a first case study of a lee-wave-influenced cirrus cloud over France, encountered during the ML-CIRRUS 2014 campaign (Voigt et al., 2017), demonstrate its applicability, and investigate the impact of both mesoscale and large-scale dynamics on the cloud structure. We end with a summary of the classification scheme and a brief outline of its potential in cirrus cloud research.

\section{Water vapor remote sensing during ML-CIRRUS}

In spring 2014, the Mid Latitude Cirrus Experiment MLCIRRUS was conducted. It was designed to investigate natural cirrus and anthropogenic contrail cirrus with regard to their nucleation, life cycle, and climate impact. In this campaign, the German research aircraft HALO, equipped with a combined in situ and remote sensing payload, performed 16 measurement flights above Europe. The on-board cloud probes, WALES lidar and novel ice residual, aerosol, trace gas, and radiation instruments probed midlatitude cirrus clouds originating from, for example, air traffic, warm conveyor belts, jet streams, or mountain waves (Voigt et al., 2017).

WALES is an airborne Differential Absorption Lidar that measures the tropospheric water vapor concentration below the research aircraft by simultaneously emitting laser pulses at three online and one offline wavelength in the water vapor absorption band around $935 \mathrm{~nm}$ (Wirth et al., 2009). The averaged pulse energy is $35 \mathrm{~mJ}$ with a repetition rate of $200 \mathrm{~Hz}$. The partly overlapping contributions from the three online wavelengths provide the needed sensitivity to compose a complete water vapor profile that ranges from just below the aircraft down to ground level. Additionally, WALES is equipped with one channel at $1064 \mathrm{~nm}$ and one high spectral resolution channel at $532 \mathrm{~nm}$ using an iodine filter. Both receiver channels are designed to detect the depolarization of the backscattered light (Esselborn et al., 2008).

WALES is capable of providing collocated measurements of humidity in the form of water vapor volume mixing ratio $r_{\mathrm{w}}$, backscatter ratio (BSR), and aerosol depolarization ratio (ADEP). Those measurements form a two dimensional curtain along the flight track of the research aircraft intersecting the atmosphere below. The lidar data we use in this paper have a vertical resolution of $15 \mathrm{~m}$. Raw data are sampled at a rate of $5 \mathrm{~Hz}$. At HALO's typical ground speed of $210 \mathrm{~m} \mathrm{~s}^{-1}$ and after averaging for a better signal-to-noise ratio, horizontal resolution is $2.5 \mathrm{~km}$ for humidity and $210 \mathrm{~m}$ for BSR and ADEP.

We use ECMWF analysis temperature data (available every $6 \mathrm{~h}$ ), with a horizontal resolution of $0.25^{\circ}$ and 91 vertical levels, which we interpolate linearly in time and bilinearly in space onto the lidar measurement cross section. Then we calculate relative humidity with respect to ice from this temperature information and the measured absolute humidity:

$\mathrm{RH}_{\mathrm{i}}=\frac{r_{\mathrm{w}} \times n_{\text {air }} \times T \times k_{\mathrm{B}}}{e_{\text {sat, } \mathrm{i}}(T)}$,

with temperature $T$, volume number density of air $n_{\text {air }}$, and Boltzmann constant $k_{\mathrm{B}}$. We use the parameterization for water vapor saturation pressure over ice $e_{\mathrm{sat}, \mathrm{i}}$ by Murphy and Koop (2005).

The accuracy of calculated relative humidity relies strongly on the quality of absolute humidity and temperature data. WALES humidity measurements exhibit a mean statistical uncertainty of 5\%. The applicability of ECMWF temperature in this calculation was investigated by Groß et al. (2014). They showed that during ascent and descent of a similar research flight in 2010, the mean temperature difference between ECMWF and on-board temperature sensors was $0.8 \mathrm{~K}$ and estimated a resulting maximum relative uncertainty of 10 to $15 \%$ as an upper boundary for the calculated $\mathrm{RH}_{\mathrm{i}}$ at typical cirrus temperatures. In cases where collocated radiosonde or dropsonde measurements are available, their temperature profiles can be used to calibrate ECMWF temperature fields, eliminating possible offsets. As modern sondes feature measurement uncertainties of down to $0.2 \mathrm{~K}$, the total relative uncertainty of $\mathrm{RH}_{\mathrm{i}}$ can therefore potentially be reduced to values as low as $6 \%$. 


\section{Cirrus evolution classification scheme}

With atmospheric lidar cross sections at hand, we are able to identify in-cloud and cloud-free regions by applying a threshold for the backscatter ratio (see Fig. 1). As there is no sharp boundary between a cloud and its surrounding, this threshold value holds a certain arbitrarity. In the case study, we use a value of 2, but in cases where, for example, thick aerosol layers are present, this threshold might need to be increased to avoid classifying parts of the aerosol layer as in-cloud regions.

Looking at cloud-free parts of the cross section, regions that might possibly lead to cirrus cloud formation can be identified by searching for data points exhibiting ice supersaturation $\left(\mathrm{RH}_{\mathrm{i}}>100 \%\right)$. Moderately supersaturated cloud-

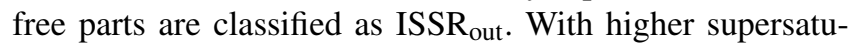
rations, the chances for the imminent nucleation of ice particles become increasingly higher. Therefore we introduce the classes $\mathrm{HET}_{\text {out }}$ and $\mathrm{HOM}_{\text {out }}$ in our classification. They represent regions outside of the cloud where onset conditions for heterogeneous and homogeneous freezing, respectively, are surpassed. Their classification is implemented via temperature-dependent humidity thresholds.

It should be noted that ice forms at the latest point, as soon as conditions for homogeneous freezing are reached, as there is always a sufficient amount of solution droplets in the atmosphere (Minikin et al., 2003). Therefore, a cloud classification should not feature considerable regions of $\mathrm{HOM}_{\text {out }}$. This fact should be kept in mind when choosing a BSR threshold value for the cloud border detection, making sure that HOM regions lie inside the cloud. However, this might not always be completely achievable without misclassifying aerosol layers (see above).

Koop et al. (2000) found that the homogeneous freezing temperatures of numerous aqueous solution droplets (1$10 \mu \mathrm{m}$ ) would fall on a single solute-independent curve, when plotted in terms of water activity $a_{w}$. They suggested that this curve could be constructed by shifting the melting point curve by $\Delta a_{\mathrm{w}}$. From experiments on homogeneous freezing, they determined a shift by $\Delta a_{\mathrm{w}}=0.305$. For atmospheric applications, water activity is equal to relative humidity, when the droplet is in equilibrium with the water vapor pressure of the surrounding air (Kärcher and Lohmann, 2002). We use these findings to extract a parameterization of the temperature-dependent onset humidity for HOM (see Table $1, \mathrm{RH}_{\mathrm{i}, \mathrm{HOM}}(T)$ ).

To determine a humidity threshold for HET, detailed information of the involved aerosol type, its coating, and size distribution would be required. Then results from laboratory experiments on onset freezing temperatures and saturations for this kind of aerosol could be used. As heterogeneous freezing conditions are still subject to current research (Hoose and Möhler, 2012) and as comprehensive aerosol information is difficult to acquire solely from remote sensing, we make only

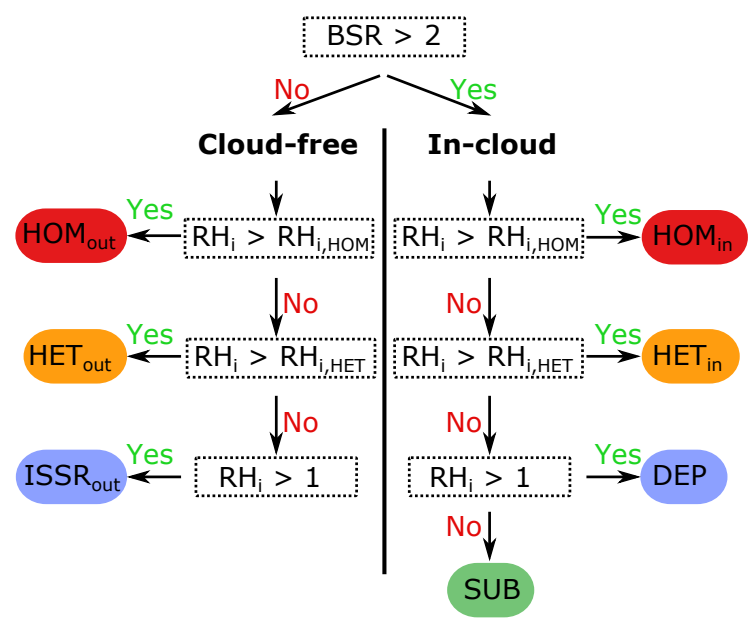

Figure 1. Cirrus evolution classification scheme based on WALES backscatter ratio (BSR) and relative humidity $\left(\mathrm{RH}_{\mathrm{i}}\right)$ derived from WALES humidity and ECMWF temperature field (description see text).

Table 1. Freezing onset humidity parameterizations.

$\begin{array}{lll}\mathrm{RH}_{\mathrm{i}, \mathrm{HOM}}(T) & =232-0.37 \mathrm{~K}^{-1} \times T & \text { Koop et al. (2000) } \\ \mathrm{RH}_{\mathrm{i}, \mathrm{HET}}^{\mathrm{MD}}(T) & =134-0.1 \mathrm{~K}^{-1} \times T & \text { Krämer et al. (2016) } \\ \mathrm{RH}_{\mathrm{i}, \mathrm{HET}}^{\mathrm{CS}}(T) & =230-0.43 \mathrm{~K}^{-1} \times T & \text { Krämer et al. (2016) }\end{array}$

a coarse distinction between two important aerosol types: mineral dust (MD) and coated soot (CS).

Together with a synergistic analysis, WALES lidar data can be used to identify the relevant aerosol type in the measurement area. To this end, we apply an aerosol classification suggested by Groß et al. (2013). It uses the fact that aerosol types can be distinguished by three intensive optical properties, aerosol lidar ratio, aerosol linear depolarization ratio, and color ratio. Mineral dust shows linear depolarization values of more than $20 \%$ and coated soot less than $20 \%$. Then we employ simplified onset parameterizations $\mathrm{RH}_{\mathrm{i}, \mathrm{HET}}^{\mathrm{MD}}(T)$ and $\mathrm{RH}_{\mathrm{i}, \mathrm{HET}}^{\mathrm{CS}}(T)$ (see Table 1 and Krämer et al., 2016, their Fig. 4). Until more detailed parameterizations are available, this imposes an uncertainty for the determination of the exact border of heterogeneous freezing regions. In contrast to $\mathrm{HOM}_{\text {out }}, \mathrm{HET}_{\text {out }}$ regions may exist in cases with no sufficient amount of aerosol ice nuclei or due to simplifications in the utilized $\mathrm{RH}_{\mathrm{i}, \mathrm{HET}}(T)$ threshold. The classes $\operatorname{ISSR}_{\text {out }}$ and $\mathrm{HET}_{\text {out }}$ represent pre-stages of cirrus formation and indicate regions where a cirrus cloud is likely to develop.

Inside of a cloud (BSR $>2$ ), we proceed in the same manner. When the $\mathrm{RH}_{\mathrm{i}, \mathrm{HOM}}(T)$ threshold is surpassed we classify this region as $\mathrm{HOM}_{\mathrm{in}}$. The region shows active ice nucleation. Together with $\mathrm{HET}_{\text {in }}$, which we classify analogously, it represents the youngest evolution stage of a cirrus cloud. HET $_{\text {in }}$ is also expected to show active nucleation as long as 
ice nuclei are present in the freezing region. However, due to the limitations mentioned above, the border of HET towards lesser supersaturated areas must be interpreted with caution. Also, ice crystals found in HET must not necessarily be formed by heterogeneous freezing, as sedimentation from higher levels featuring different nucleation conditions may take place. Still, heterogeneous freezing is an important freezing mechanism in midlatitudes (Cziczo et al., 2013) and the class $\mathrm{HET}_{\text {in }}$ adds more information to the classification, leading to a more complete characterization of cirrus clouds.

When relative humidity inside the cloud is lower than the freezing thresholds, we classify as DEP, as the remaining supersaturation is depleted by deposition of water vapor onto the existing ice particles. This intermediate evolution stage is dominated by depositional growth of ice crystals. The final evolution stage of a cloud sets in, when relative humidity falls below $100 \%$. In such an environment ice inevitably must sublimate. We classify this region as SUB.

During the life cycle of a cloud, nucleation, growth and sublimation events may occur more than once, e.g., when atmospheric dynamics cause renewed updrafts and a second freezing event on top of pre-existing ice takes place. As described, our method is able to identify nucleation, growth, sublimation regions and pre-stages of cloud formation. However on its own, it does not yield any information about earlier developments of those regions. Its very strength is to reveal the actual atmospheric state with regards to cirrus evolution at the time of measurement. This is done on a high spatial resolution that exceeds typical resolutions of GCMs, enabling the detailed study of individual cloud parts.

\section{Case study ML-CIRRUS 2014-03-29}

We demonstrate the applicability of our classification scheme in a cirrus case that was obtained during the ML-CIRRUS field campaign on 29 March 2014. The meteorological situation over western Europe and the Iberian Peninsula on the flight day is dominated by a trough extending from the west of Ireland to the Iberian Peninsula and further to the western part of northern Africa (Fig. 2a). At $300 \mathrm{hPa}$, high southerly winds with wind speeds up to $35 \mathrm{~m} \mathrm{~s}^{-1}$ are observed on the leading edge over southern France and Spain. Two days before the research flight, model forecasts indicated the existence of cirrus forming from high updrafts over the Pyrenees, as well as cirrus influenced by lee waves north of the mountain ridge. Additionally, highly dust-loaded air masses over southern France, originating from Saharan dust events over Algeria were expected.

In this meteorological setting the research flight was performed with the aim of sampling all stages of cirrus evolution that resulted from an overflow of the Pyrenees with high wind speeds and consequent gravity wave excitations in the lee of the mountain ridge. Therefore, the flight path in the relevant measurement region was chosen to run along the main wind direction, sampling the clouds along their path of advection.

The flight (Fig. 2, red flight path) started in Oberpfaffenhofen, Germany at 12:37 UTC and first went westward towards Paris, followed by a southward flight leg towards Spain at an altitude of $11200 \mathrm{~m}$. The investigated cirrus cloud was encountered over southern France during this leg, which runs with a bearing of $190^{\circ}$ (white flight leg). Inside cirrus clouds, over the Pyrenees mountains, three legs at different lower altitudes followed. From the Mediterranean coast the aircraft turned eastward and probed cirrus at several altitudes near the Balearic Islands before it went northward towards Oberpfaffenhofen (landing at 19:50 UTC).

\subsection{Cirrus leg overview}

The following discussion of the classification scheme focuses on the southward flight leg stretching about $400 \mathrm{~km}$ to the north and $200 \mathrm{~km}$ to the south of the Pyrenees (Fig. 2, white flight path). Figure $2 \mathrm{~b}$ shows a false-color image of the Pyrenees area derived from SEVIRI (Spinning Enhanced Visible and Infrared Imager) data at 14:30 UTC. The red, green, and blue color channels of the image take SEVIRI's $635 \mathrm{~nm}, 850 \mathrm{~nm}$, and inverted $10.8 \mu \mathrm{m}$ channel data. This way, the high and therefore cool cirrus clouds stand out with a bluish color. Low clouds are depicted in yellow and the surface of the Earth has a green tone. Coming from the north, the flight path intersects an ice cloud that is part of a larger cloud regime expanding from southern France towards the Algerian coast. This cloud is followed by a completely cloud-free area north of the Pyrenees. Over the mountain ridge some localized high clouds are crossed.

Earlier satellite pictures and ECMWF data (not shown) indicate that the cirrus cloud regime formed under the influence of a highly humid air mass stemming from southern Spain that also shows the tendency to produce lower liquid clouds. As the air mass is transported to the north, it is impacted by gravity waves generated when crossing the Pyrenees. The analysis of preliminary temperature data (not shown) provided by the on-board, passive Microwave Temperature Profiler (Denning et al., 1989) shows that temperature oscillations, caused by gravity waves, continue to exist inside the cirrus cloud intersected by the flight path.

In Fig. 3 we plot a cross section showing backscatter ratio at a wavelength of $532 \mathrm{~nm}$ along the chosen part of the flight path. Here atmospheric features apparent in Fig. 2 can be studied in greater detail. On the lee side, north of the Pyrenees (14:19-14:34 UTC), a high cirrus cloud is observed that extends from a height of 7 to $10.4 \mathrm{~km}$. The southern and middle parts are dominated by high BSR values from 50 up to 200, whereas the northern section exhibits lower values. Aerosol linear depolarization ratios of more than $30 \%$ inside the cloud (not shown) and temperatures below $240 \mathrm{~K}$ clearly indicate a pure ice cloud. Over the Pyrenees (14:4214:53 UTC) a lower cirrus cloud is located at an altitude of 

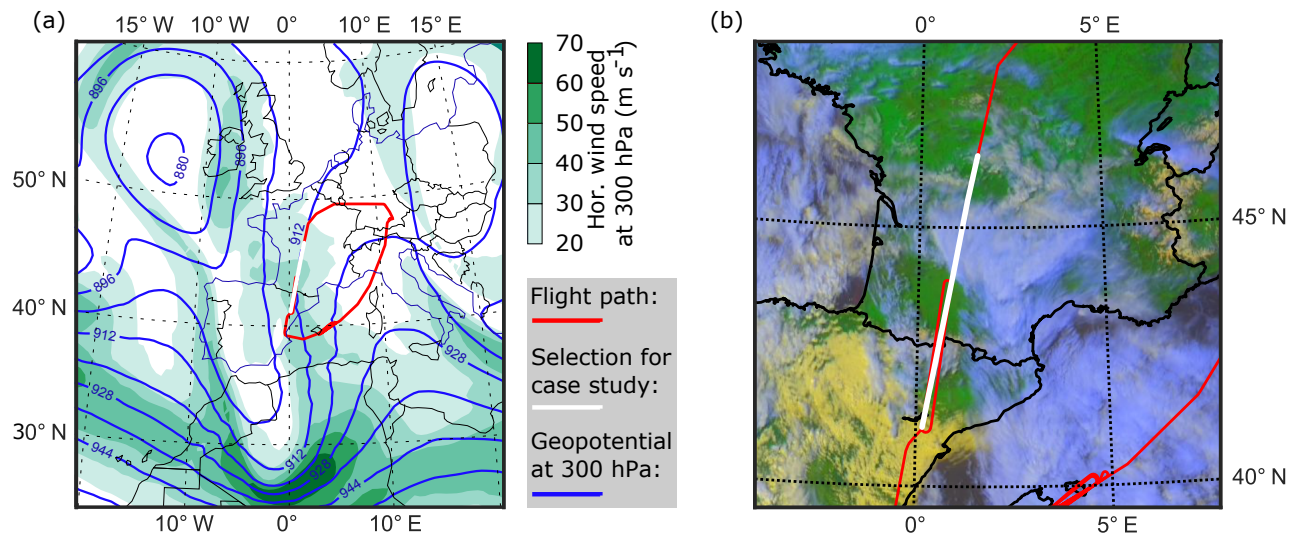

Figure 2. Meteorological situation on 29 March 2014 over western Europe: (a) ECMWF analysis data (12:00 UTC) at 300 hPa of geopotential (blue isolines) and horizontal wind speed (shaded green). (b) SEVIRI false-color image taken at 14:30 UTC (see text). High ice clouds have a blue color, lower liquid clouds are yellow, cloud-free ground has green color. The path of the research flight is plotted in red and the flight leg used in the case study (14:16-14:58 UTC) is marked white.

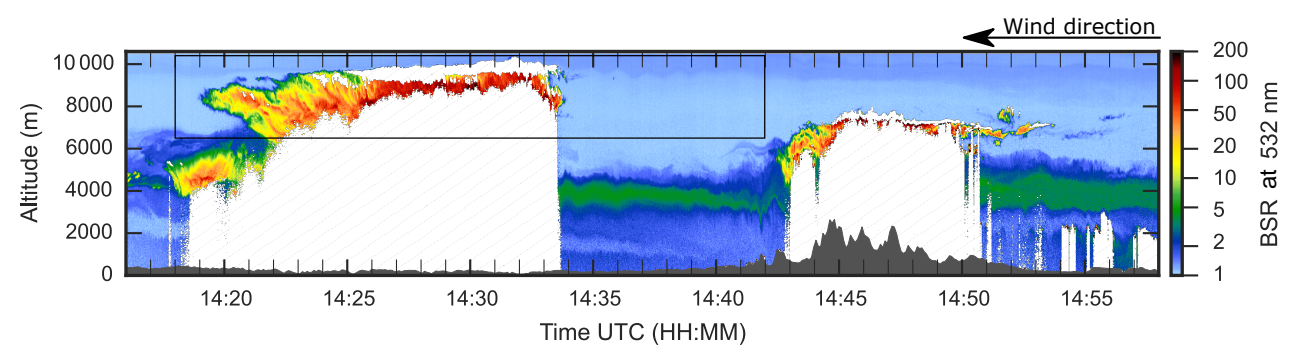

Figure 3. Backscatter ratio (BSR) at $532 \mathrm{~nm}$ measured along the flight path (white line in Fig. 2). Hatched areas indicate data that were excluded due to detector saturation or low signal-to-noise ratio and the terrain profile is shown in dark gray. The black rectangle marks the cirrus region that is studied further (see Figs. 4 and 5). The arrow shows the main wind direction at cirrus level.

about $6 \mathrm{~km}$. Its spatially restricted occurrence over the mountain ridge indicates a formation due to forced updrafts stemming from the southerly cross-mountain flow. Even lower, at a height of $4 \mathrm{~km}$ a thick aerosol layer is discernible. An analysis of ADEP shows values between 20 and $30 \%$, typical for Saharan mineral dust (Groß et al., 2013) which is consistent with the origin of the air masses in northern Africa, as forecasted by dust models.

Furthermore, in the region between the two clouds (14:3414:43 UTC) gravity lee waves are discernible at an altitude of about $9500 \mathrm{~m}$ and also in the lower aerosol layer. These waves are expected to influence at least parts of the northern cirrus cloud. We will investigate them in more detail in Sect. 4.3.

\subsection{Classifying evolution stages}

In the following we will apply our classification scheme to the high cirrus cloud north of the Pyrenees. Figures 4 and 5 give a close-up view of the selected data marked with a black rectangle in Fig. 3. Water vapor volume mixing ratio $r_{\mathrm{W}}$ measured by WALES is plotted in Fig. 4a, together with red isolines of ECMWF temperature. A black contour line $(\mathrm{BSR}=2)$ marks the cloud border. Being an absolute humidity measure, $r_{\mathrm{w}}$ generally decreases with increasing altitude, as temperature is decreasing and almost all sources of water vapor are located at the Earth's surface. Contrastingly, a humid layer, surrounded by dryer air at a height of approximately $9000 \mathrm{~m}$, can be found upstream of the cirrus cloud (14:34-14:40 UTC). In this region, the water vapor data exhibit the same oscillations as previously seen in the BSR data.

Relative humidity with respect to ice (Fig. 4b) is calculated from this data using the ECMWF model temperature field. As expected, supersaturated regions (blue) are found mostly inside of the cirrus. There are also major subsaturated regions (red) in the northern part of the cloud. South of the cirrus, high supersaturations exist in cloud-free air, mostly in the crests of the gravity waves (14:34-14:36 UTC). The highest supersaturations are measured in the most southern part of the cloud (14:33-14:34 UTC). They indicate a nucleation region.

To investigate individual parts of the cloud in more detail, we apply our classification and visualize the result in Fig. 5. Data pixels are classified (Sect. 3.2) and marked in color accordingly, and in-cloud and cloud-free regions can be dis- 


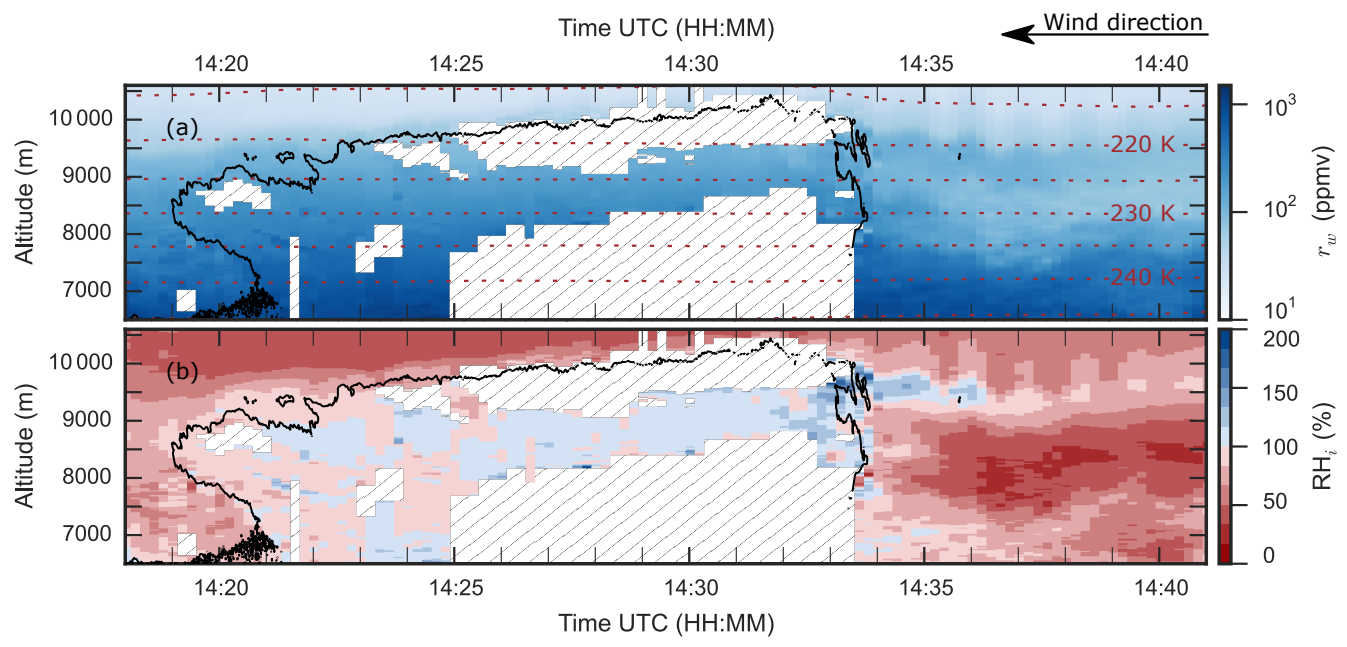

Figure 4. Humidity data of cirrus marked in Fig. 3: (a) water vapor mixing ratio $r_{\mathrm{w}}$ as measured with WALES and ECMWF temperature contour lines. (b) Relative humidity with respect to ice $\mathrm{RH}_{\mathrm{i}}$ derived from WALES data and ECMWF temperature field. The cirrus is outlined by a black contour line $(\mathrm{BSR}=2)$ and invalid data are marked by black hatching.

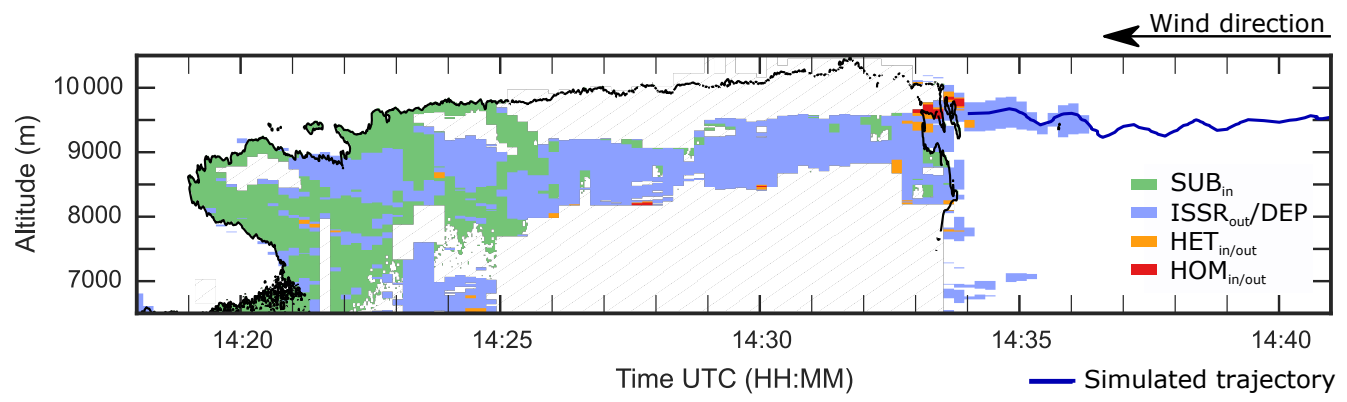

Figure 5. Classified evolution regions of cirrus cloud. In-cloud and cloud-free regions can be distinguished by the black contour line of $\mathrm{BSR}=2$. Regions of ice nucleation $\left(\mathrm{HOM}_{\text {in/out }}, \mathrm{HET}_{\text {in/out }}\right)$, ice supersaturation outside (ISSR out), and depositional growth (DEP) and subsaturation (SUB) inside the cloud are visualized. Subsaturated regions outside the cloud are left blank and invalid data are marked by black hatching. The blue line shows a trajectory used for simulation of adiabatic cooling (see Sect. 4.3 and Fig. 7).

tinguished by the black contour line for a BSR value of 2 . Heterogeneous freezing is identified using the HET threshold for coated soot $\left(\mathrm{RH}_{\mathrm{i}, \mathrm{HET}}^{\mathrm{CS}}(T)\right)$. We base this decision on $48 \mathrm{~h}$ backward trajectory calculations of air masses at 8.5 to $9.5 \mathrm{~km}$ (not shown) that indicate no influence from lower Saharan dust-loaded levels. Subsaturated regions outside of the cloud are left blank and areas where no valid data are available are indicated by black hatching.

The abovementioned humid layer, discernible in Fig. 4, reaches ice supersaturation (ISSR) in the two crests of the gravity lee wave to the south of the cloud (14:3414:36 UTC). At the cloud edge, the HET and HOM freezing thresholds are also surpassed (14:33-14:34 UTC). As no relevant isolated HET region exists and HOM freezing also sets in at the cloud edge, we assume that homogeneous freezing might be the dominant freezing mechanism here. This upper, southern section of the cirrus is dominated by ice nucleation and represents the youngest part of the cloud.
The top level of the cloud and the ISSR south of it climbs from about 9.3 to $10.4 \mathrm{~km}$ at 14:31:50 UTC. Considering the speed of the aircraft $\left(200 \mathrm{~m} \mathrm{~s}^{-1}\right)$ and the wind speed (about $30 \mathrm{~m} \mathrm{~s}^{-1}$ in opposite direction), and assuming that the found pattern is stationary (more in Sect. 4.3), this corresponds to a vertical velocity of about $50 \mathrm{~cm} \mathrm{~s}^{-1}$. In the temperature range between 200 and $220 \mathrm{~K}$, such high vertical velocities typically lead to high ice crystal number densities with small ice particles $\left(r_{0}<10 \mu \mathrm{m}\right.$; Kärcher and Lohmann, 2002). As the updraft region is observed between 14:32 and 14:36 UTC, we assume that freezing takes place at least between the cloud edge and the peak of the cloud top at 14:31:50 UTC, although no valid data are available for parts of the upper cloud due to detector saturation.

In the middle (14:26-14:32 UTC), a section of moderate supersaturation (DEP) is located. This is an already well developed part of the cirrus that is dominated by depositional growth of ice crystals. After the initial ascent (14:32- 
14:34 UTC), the cloud top slopes from over $10 \mathrm{~km}$ down to under $9 \mathrm{~km}$ at the northern edge, corresponding to a vertical velocity of about $-30 \mathrm{~cm} \mathrm{~s}^{-1}$. Sedimentation may contribute to this, but sub- $10 \mu \mathrm{m}$ particles are rather associated with fall speeds of under $2 \mathrm{~cm} \mathrm{~s}^{-1}$ (Gasparini et al., 2016, their Fig. 1). This large-scale descent, also apparent in ECMWF model data (not shown), reduces supersaturation and evokes the intermediate DEP region as well as large connected regions of subsaturation (SUB) in the northern part of the cloud (14:1914:26 UTC). Here the cloud is starting to break up, as ice particles are sublimating.

From these results all cirrus evolution stages can be identified: from cloud-free ISSR and ice nucleation (HET, HOM) aided by vertical displacements in a gravity lee wave, to crystal growth by deposition of water vapor in a moderately supersaturated region DEP, to the dissolving of the cloud in a subsaturated region (SUB), caused by a large-scale descent.

The spatial distribution of these major stages of cirrus evolution feature a horizontal component with ice nucleation in the south and dissipation in the north. Also, we find SUB regions at the cloud top level, in part, located above DEP regions in the north of the cloud (Fig. 5). Our findings fit well into the perspective of model simulations, investigating the influence of dynamics on the evolution of a cirrus cloud (Spichtinger and Gierens, 2009) that also found more complex horizontal distributions deviating from a simplistic cirrus evolution pattern comprising ice nucleation at cloud top level, a crystal growth in the middle and sublimation at the bottom. Thus our classification illustrates how the large-scale meteorological context, wind, and gravity wave fields can affect the structure of individual clouds.

Unfortunately, no dropsonde temperature measurements were conducted in this cirrus case. Thus we must assume a relative uncertainty of $\mathrm{RH}_{\mathrm{i}}$ between 10 and $15 \%$ at cirrus level (see Sect. 2). This directly translates into an uncertainty in locating the exact border between evolution stages. However, we found that the horizontal distribution order and the existence of SUB regions at the cloud top continue to exist even after offsetting the temperature field by $\pm 0.8 \mathrm{~K}$. Therefore we are confident that ECMWF temperature data are suitable for this kind of analysis.

\subsection{Investigating the influence of lee waves}

A special feature of this case study is the presence of lee wave patterns in the cloud region. Figure 6 gives a close-up view of BSR data in the cloud-free area south of the cirrus cloud. A layer of slightly higher BSR $(>1.2)$ is located above an altitude of $9500 \mathrm{~m}$. It shows clear oscillations at its boundary to a lower, cleaner layer of air. One period extends over about $66 \mathrm{~s}$ in measurement time, which corresponds to an apparent wavelength of $14 \mathrm{~km}$ with vertical displacements of up to $190 \mathrm{~m}$.

ECMWF model data, available for this cirrus case, features a horizontal grid spacing of about $16 \mathrm{~km}$ and thus

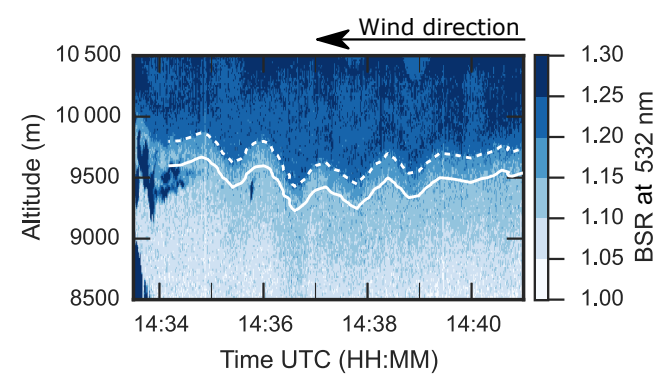

Figure 6. Close-up view of BSR data in the lee wave region south to the cirrus cloud. Dotted line: contour line $(\mathrm{BSR}=1.2)$; solid line: trajectory used for simulation (contour line shifted by $200 \mathrm{~m}$ ).

ECMWF is not able to resolve the mesoscale lee waves in its temperature gradients (see Fig. 4a). As a result, temperatures in the crests might be even lower and $\mathrm{RH}_{\mathrm{i}}$ values are therefore underestimated.

To investigate this possible deviation and its influence on our classification results, we simulate adiabatic cooling of an air parcel along a hypothesized trajectory (Figs. 5 and 6) in front of the cirrus cloud. The trajectory runs $200 \mathrm{~m}$ under and parallel to the contour line of $\mathrm{BSR}=1.2$ (Fig. 6), that separates the two distinct layers of air. The wind direction in this region differs by less than $10^{\circ}$ from the flight path. This makes us confident that the simulated trajectory resembles a real trajectory reasonably well, under the assumption of a stationary air flow.

SEVIRI images from 14:00 and 15:00 UTC (not shown) indicate that the northern and southern edges of the cloud are only moving about $20 \mathrm{~km}$ to the north along the flight path. That corresponds to a cloud velocity of under $6 \mathrm{~m} \mathrm{~s}^{-1}$, compared to wind speeds of up to $35 \mathrm{~m} \mathrm{~s}^{-1}$ at cirrus altitude. Similar to real lee wave clouds (Field et al., 2012), air is flowing through the region, becoming part of the cloud in the south and leaving the cloud in the north. In the confined area and time frame of our simulation, we consider the underlying wind and wave fields to be quasi-stationary. However this might certainly not be true for the duration of the whole flight leg (14:18-14:41 UTC). Also, our simulation is not intended to provide corrected temperature data but to illustrate the general influence of gravity waves on cloud formation and of unresolved temperature fluctuations on our classification.

Along this trajectory we calculated peak vertical velocities of up to $120 \mathrm{~cm} \mathrm{~s}^{-1}$, more than twice as high as the average vertical velocity of $50 \mathrm{~cm} \mathrm{~s}^{-1}$ in the initial updraft region, estimated in Sect. 4.2. During nucleation, such peaks may lead to even smaller ice crystals and higher ice crystal number densities of up to $50 \mathrm{~cm}^{-1}$.

In Fig. 7, ECMWF temperature and relative humidity calculated with ECMWF temperature along the trajectory are plotted (blue) as a function of measurement time. As the trajectory follows the vertical displacements of the grav- 

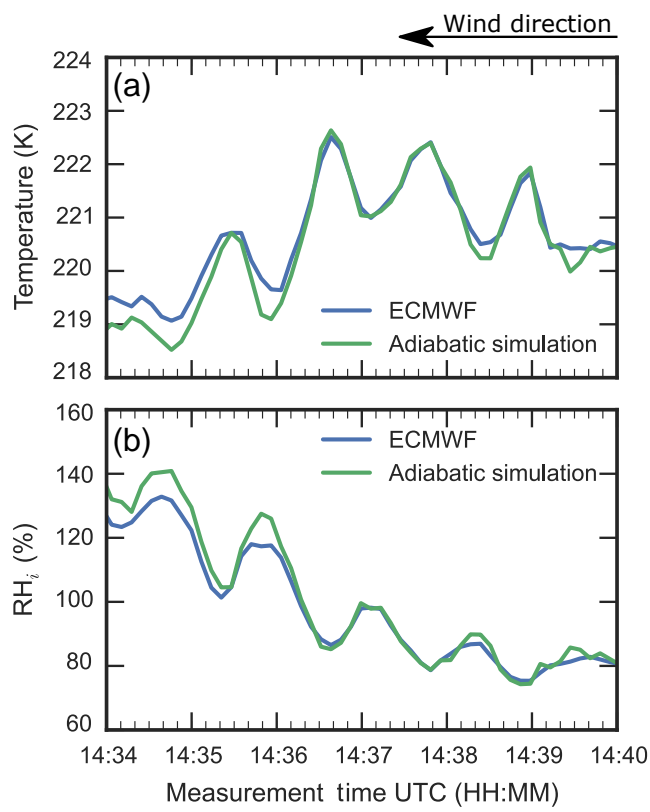

Figure 7. Simulation of temperature $T$ and relative humidity $\mathrm{RH}_{\mathrm{i}}$. Green lines are simulated values along a derived trajectory (Fig. 5) assuming adiabatic cooling and heating within the gravity wave, respectively. In blue are ECMWF values interpolated to the trajectory location.

ity wave along the wind direction, i.e. from right to left in Figs. 3 to 7, relative humidity and ECMWF temperature show oscillations. They stem from the undisturbed temperature gradient, as ECMWF does not resolve the mesoscale lee waves. Besides clear oscillations, a development towards higher $\mathrm{RH}_{\mathrm{i}}$ and lower temperature, approaching the cloud, is discernible. From 14:36:20 UTC on, $\mathrm{RH}_{\mathrm{i}}$ shows supersaturation and reaches values of 120 and $130 \%$ in the following two crests, surpassing the HET threshold.

Now we start a parcel at the beginning of the trajectory (measurement time: 14:40 UTC) initialized with the ECMWF temperature at this point. As it follows the trajectory, the temperature is calculated from its vertical displacement using the dry adiabatic temperature gradient. The simulated temperature and relative humidity is plotted in green. Compared to ECMWF, the temperature in the last two crests south of the cloud edge is more than $0.5 \mathrm{~K}$ lower and values of $\mathrm{RH}_{\mathrm{i}}$ are higher by $10 \%$. The deviations result from the nonadiabatic temperature gradient in the ECMWF data.

These results emphasize the role of lee waves in the most southern part of the studied cirrus cloud. Comparably cooler temperatures due to adiabatic cooling in the wave crests facilitate the early nucleation of ice crystals. We find that our classification, using original ECMWF data with relatively coarse spatial resolution (horizontal grid spacing: $16 \mathrm{~km}$ ), is able to reveal the relevant classification features within the gravity wave region. The classification quality will be even better in cases where data from the latest ECMWF model implemen- tation, with an improved grid spacing of $9 \mathrm{~km}$, or output from regional models are available.

Overall our classification proved to be applicable in a meteorological context that comprises both mesoscale and large-scale dynamics. It identifies all relevant stages of cirrus evolution and their detailed spatial distribution and thus also reveals the influences of gravity waves and large-scale atmospheric motion on the studied cirrus cloud.

\section{Summary and conclusions}

We presented a novel cirrus classification scheme capable of identifying all relevant stages of cirrus cloud evolution. It is based on airborne lidar measurements with high spatial resolution of water vapor, backscatter, and aerosol depolarization. This data are used together with ECMWF model temperature fields and knowledge and assumptions about onset conditions for homogeneous and heterogeneous freezing, to retrieve a cross section of the cloud, revealing the detailed distribution of evolution stages.

In cloud-free air $(B S R<2)$, ice supersaturated regions $\left(\mathrm{ISSR}_{\mathrm{out}}\right)$ as well as regions of homogeneous $\left(\mathrm{HOM}_{\mathrm{out}}\right)$ and heterogeneous freezing $\left(\mathrm{HET}_{\text {out }}\right)$ are determined. These indicate favorable areas for cirrus cloud formation. Inside of a cloud, ice nucleation $\left(\mathrm{HET}_{\text {in }}, \mathrm{HOM}_{\text {in }}\right)$, depositional growth (DEP), and sublimation regions (SUB) are distinguished. They represent the formation, growing, and breakup phases of a cirrus cloud, respectively.

We demonstrated the applicability of our classification in a first case study of a cirrus cloud that was observed in a complex meteorological situation comprising a thick aerosol layer, large-scale dynamics, and mesoscale gravity lee waves. Here it revealed a nonstandard horizontal order of the aforementioned evolution stages and helped to identify the influence of underlying wind and gravity wave conditions as well as large-scale dynamics on individual parts of the cloud.

With this valuable tool at hand, in our ongoing research we are investigating the large airborne lidar data set obtained during the ML-CIRRUS campaign. This classification scheme facilitates the study of the spatial distribution of evolution stages and can be used to set in situ and other remote sensing data, obtained during the campaign, in relation to cirrus evolution. By bringing together those data sources, the specific optical and microphysical properties of different cirrus stages can now be explored. The possibility of combining our classification with trajectory-based methods promises to reveal details of the temporal succession of evolution stages. Thus, we aim to achieve more detailed insights in radiative properties of cirrus clouds under various formation and life cycle conditions. 
Data availability. The data used in this work are accessible on request via the HALO database with dataset IDs: \#4992, \#4993 and \#4994 (DLR, 2017a, b, c).

Competing interests. The authors declare that they have no conflict of interest.

Acknowledgements. ML-CIRRUS campaign was mainly funded by Deutsches Zentrum für Luft- und Raumfahrt (DLR) and Deutsche Forschungsgemeinschaft (DFG). This work has been funded by the DLR VO-R young investigator group. The authors would like to thank the staff members of the HALO aircraft from DLR Flight Experiments for preparing and performing the measurement flights, Christiane Voigt, Andreas Minikin and everybody contributing to the successful planning and execution of ML-CIRRUS, the European Centre for Medium-Range Weather Forecasts (ECMWF) for providing model data, and Mareike Kenntner for providing preliminary MTP temperature data. Our special thanks go to Florian Ewald for providing SEVIRI satellite image data and Klaus Gierens and Benedikt Ehard for fruitful discussions and helpful suggestions that contributed to the quality of this work.

The article processing charges for this open-access

publication were covered by a Research

Centre of the Helmholtz Association.

Edited by: D. Baumgardner

Reviewed by: three anonymous referees

\section{References}

Baran, A. J.: A review of the light scattering properties of cirrus, J. Quant. Spectrosc. R., 110, 1239-1260, doi:10.1016/j.jqsrt.2009.02.026, 2009.

Baran, A. J.: From the single-scattering properties of ice crystals to climate prediction: A way forward, Atmos. Res., 112, 45-69, doi:10.1016/j.atmosres.2012.04.010, 2012.

Bogdan, A. and Molina, M. J.: Why does large ice supersaturation persist in cold cirrus clouds?, J. Phys. Chem. A, 113, 1412314130, 2009.

Comstock, J. M., Ackerman, T. P., and Turner, D. D.: Evidence of high ice supersaturation in cirrus clouds using ARM Raman lidar measurements, Geophys. Res. Lett., 31, L11106, doi:10.1029/2004GL019705, 2004.

Cziczo, D. J., Froyd, K. D., Hoose, C., Jensen, E. J., Diao, M., Zondlo, M. A., Smith, J. B., Twohy, C. H., and Murphy, D. M.: Clarifying the Dominant Sources and Mechanisms of Cirrus Cloud Formation, Science, 340, 1320-1324, doi:10.1103/PhysRevB.60.7764, 2013.

DeMott, P. J., Prenni, A. J., Liu, X., Kreidenweis, S. M., Petters, M. D., Twohy, C. H., Richardson, M. S., Eidhammer, T., and Rogers, D. C.: Predicting global atmospheric ice nuclei distribu- tions and their impacts on climate, P. Natl. Acad. Sci. USA, 107, 11217-11222, doi:10.1073/pnas.0910818107, 2010.

Denning, R. F., Guidero, S. L., Parks, G. S., and Gary, B. L.: Instrument description of the airborne microwave temperature profiler, J. Geophys. Res., 94, 16757-16765, 1989.

Dinh, T., Fueglistaler, S., Durran, D., and Ackerman, T.: Cirrus and water vapour transport in the tropical tropopause layer Part 2: Roles of ice nucleation and sedimentation, cloud dynamics, and moisture conditions, Atmos. Chem. Phys., 14, 1222512236, doi:10.5194/acp-14-12225-2014, 2014.

DLR: \#4992, ML-CIRRUS_6_WALES_20140329a_ADEP532_L1 _V1.nc, available at: https://halo-db.pa.op.dlr.de/dataset/4992, last access: 3 May 2017a.

DLR: \#4993, ML-CIRRUS_6_WALES_20140329a_H2O_L1_ V1.nc, available at: https://halo-db.pa.op.dlr.de/dataset/4993, last access: 3 May 2017b.

DLR: \#4994, ML-CIRRUS_6_WALES_20140329a_BSR532P_L1 _V1.nc, available at: https://halo-db.pa.op.dlr.de/dataset/4994, last access: 3 May 2017c.

Esselborn, M., Wirth, M., Fix, A., Tesche, M., and Ehret, G.: Airborne high spectral resolution lidar for measuring aerosol extinction and backscatter coefficients., Appl. Optics, 47, 346-358, doi:10.1364/AO.47.000346, 2008.

Field, P. R., Cotton, R. J., Noone, K., Glantz, P., Kaye, P. H., Hirst, E., Greenaway, R. S., Jost, C., Gabriel, R., Reiner, T., Andreae, M., Saunders, C. P. R., Archer, A., Choularton, T., Smith, M., Brooks, B., Hoell, C., Bandy, B., Johnson, D., and Heymsfield, A.: Ice nucleation in orographic wave clouds: Measurements made during INTACC, Q. J. Roy. Meteor. Soc., 127, 1493-1512, 2001.

Field, P. R., Heymsfield, A. J., Shipway, B. J., Demott, P. J., Pratt, K. A., Rogers, D. C., Stith, J., and Prather, K. A.: Ice in clouds experiment-layer clouds. Part II: Testing characteristics of heterogeneous ice formation in lee wave clouds, J. Atmos. Sci., 69, 1066-1079, doi:10.1175/JAS-D-11-026.1, 2012.

Gallagher, M. W., Connolly, P. J., Crawford, I., Heymsfield, A., Bower, K. N., Choularton, T. W., Allen, G., Flynn, M. J., Vaughan, G., and Hacker, J.: Observations and modelling of microphysical variability, aggregation and sedimentation in tropical anvil cirrus outflow regions, Atmos. Chem. Phys., 12, 66096628, doi:10.5194/acp-12-6609-2012, 2012.

Gasparini, B., Münch, S., Poncet, L., Feldmann, M., and Lohmann, U.: Is increasing ice crystal sedimentation velocity in geoengineering simulations a good proxy for cirrus cloud seeding?, Atmos. Chem. Phys. Discuss., doi:10.5194/acp-2016-1109, in review, 2016.

Groß, S., Esselborn, M., Weinzierl, B., Wirth, M., Fix, A., and Petzold, A.: Aerosol classification by airborne high spectral resolution lidar observations, Atmos. Chem. Phys., 13, 2487-2505, doi:10.5194/acp-13-2487-2013, 2013.

Groß, S., Wirth, M., Schäfler, A., Fix, A., Kaufmann, S., and Voigt, C.: Potential of airborne lidar measurements for cirrus cloud studies, Atmos. Meas. Tech., 7, 2745-2755, doi:10.5194/amt-72745-2014, 2014.

Heymsfield, A.: Cirrus Uncinus Generating Cells and the Evolution of Cirriform Clouds. Part I: Aircraft Observations of the Growth of the Ice Phase, J. Atmos. Sci., 32, 799-808, doi:10.1175/15200469(1975)032<0799:CUGCAT>2.0.CO;2, 1975. 
Heymsfield, A. J. and Miloshevich, L. M.: Relative Humidity and Temperature Influences on Cirrus Formation and Evolution: Observations from Wave Clouds and FIRE II, J. Atmos. Sci., 52, 4302-4326, doi:10.1175/15200469(1995)052<4302:RHATIO>2.0.CO;2, 1995.

Hoose, C. and Möhler, O.: Heterogeneous ice nucleation on atmospheric aerosols: a review of results from laboratory experiments, Atmos. Chem. Phys., 12, 9817-9854, doi:10.5194/acp-12-98172012, 2012.

Jackson, R. C., McFarquhar, G. M., Fridlind, A. M., and Atlas, R.: The dependence of cirrus gammasize distributions expressed as volumes in $N_{0}-\lambda-\mu$ phase space and bulk cloud properties on environmental conditions: Results from the Small Ice Particles in Cirrus Experiment (SPARTICUS), J. Geophys. Res.-Atmos., 120, 10351-10377, doi:10.1002/2015JD023492, 2015.

Kärcher, B. and Lohmann, U.: A parameterization of cirrus cloud formation: Homogeneous freezing of supercooled aerosols, J. Geophys. Res., 107, 4010, doi:10.1029/2001jd000470, 2002.

Koop, T., Luo, B., Tsias, A., and Peter, T.: Water Activity as the Determinant for Homogeneous Ice Nucleation in Aqueous Solutions, Nature, 406, 611-614, 2000.

Korolev, A. and Isaac, G. A.: Relative Humidity in Liquid, Mixed-Phase, and Ice Clouds, J. Atmos. Sci., 63, 2865-2880, doi:10.1175/JAS3784.1, 2006.

Korolev, A. V. and Mazin, I. P.: Supersaturation of Water Vapor in Clouds, J. Atmos Sci., 60, 2957-2974, doi:10.1175/15200469(2003)060<2957:SOWVIC>2.0.CO;2, 2003.

Krämer, M., Schiller, C., Afchine, A., Bauer, R., Gensch, I., Mangold, A., Schlicht, S., Spelten, N., Sitnikov, N., Borrmann, S., de Reus, M., and Spichtinger, P.: Ice supersaturations and cirrus cloud crystal numbers, Atmos. Chem. Phys., 9, 3505-3522, doi:10.5194/acp-9-3505-2009, 2009.

Krämer, M., Rolf, C., Luebke, A., Afchine, A., Spelten, N., Costa, A., Meyer, J., Zöger, M., Smith, J., Herman, R. L., Buchholz, B., Ebert, V., Baumgardner, D., Borrmann, S., Klingebiel, M., and Avallone, L.: A microphysics guide to cirrus clouds - Part 1: Cirrus types, Atmos. Chem. Phys., 16, 3463-3483, doi:10.5194/acp16-3463-2016, 2016.

Kübbeler, M., Hildebrandt, M., Meyer, J., Schiller, C., Hamburger, Th., Jurkat, T., Minikin, A., Petzold, A., Rautenhaus, M., Schlager, H., Schumann, U., Voigt, C., Spichtinger, P., Gayet, J.-F., Gourbeyre, C., and Krämer, M.: Thin and subvisible cirrus and contrails in a subsaturated environment, Atmos. Chem. Phys., 11, 5853-5865, doi:10.5194/acp-11-5853-2011, 2011.

Minikin, A., Petzold, A., Ström, J., Krejci, R., Seifert, M., van Velthoven, P., Schlager, H., and Schumann, U.: Aircraft observations of the upper tropospheric fine particle aerosol in the Northern and Southern Hemispheres at midlatitudes, Geophys. Res. Lett., 30, 1503, doi:10.1029/2002GL016458, 2003.

Muhlbauer, A., Ackerman, T. P., Comstock, J. M., Diskin, G. S., Evans, S. M., Lawson, R. P., and Marchand, R. T.: Impact of large-scale dynamics on the microphysical properties of midlatitude cirrus, J. Geophys. Res.-Atmos., 119, 3976-3996, doi:10.1002/2013JD020035, 2014.

Murphy, D. M. and Koop, T.: Review of the vapour pressures of ice and supercooled water for atmospheric applications, Q. J. Roy. Meteor. Soc., 131, 1539-1565, doi:10.1256/qj.04.94, 2005.
Pruppacher, H. R. and Klett, J. D.: Microphysics of Clouds and Precipitation, in: Atmospheric and Oceanographic Science Library, vol. 18, Springer, Dordrecht, the Netherlands, 2010.

Schnaiter, M., Järvinen, E., Vochezer, P., Abdelmonem, A., Wagner, R., Jourdan, O., Mioche, G., Shcherbakov, V. N., Schmitt, C. G., Tricoli, U., Ulanowski, Z., and Heymsfield, A. J.: Cloud chamber experiments on the origin of ice crystal complexity in cirrus clouds, Atmos. Chem. Phys., 16, 5091-5110, doi:10.5194/acp16-5091-2016, 2016.

Spichtinger, P.: Shallow cirrus convection - a source for ice supersaturation, Tellus A, 66, 19937, doi:10.3402/tellusa.v66.19937, 2014.

Spichtinger, P. and Gierens, K. M.: Modelling of cirrus clouds Part 1b: Structuring cirrus clouds by dynamics, Atmos. Chem. Phys., 9, 707-719, doi:10.5194/acp-9-707-2009, 2009.

Spichtinger, P. and Krämer, M.: Tropical tropopause ice clouds: a dynamic approach to the mystery of low crystal numbers, Atmos. Chem. Phys., 13, 9801-9818, doi:10.5194/acp-13-98012013, 2013.

Spichtinger, P., Gierens, K., and Read, W.: The global distribution of ice-supersaturated regions as seen by the Microwave Limb Sounder, Q. J. Roy. Meteor. Soc., 129, 3391-3410, doi:10.1256/qj.02.141, 2003.

Spichtinger, P., Gierens, K., and Dörnbrack, A.: Formation of ice supersaturation by mesoscale gravity waves, Atmos. Chem. Phys. 5, 1243-1255, doi:10.5194/acp-5-1243-2005, 2005a.

Spichtinger, P., Gierens, K., and Wernli, H.: A case study on the formation and evolution of ice supersaturation in the vicinity of a warm conveyor belt's outflow region, Atmos. Chem. Phys., 5, 973-987, doi:10.5194/acp-5-973-2005, 2005b.

Voigt, C., Schumann, U., Minikin, A., Abdelmonem, A., Afchine, A., Borrmann, S., Boettcher, M., Buchholz, B., Bugliaro, L., Costa, A., Curtius, J., Dollner, M., Dörnbrack, A., Dreiling, V., Ebert, V., Ehrlich, A., Fix, A., Forster, L., Frank, F., Fütterer, D., Giez, A., Graf, K., Grooß, J., Groß, S., Heimerl, K., Heinold, B., Hüneke, T., Järvinen, E., Jurkat, T., Kaufmann, S., Kenntner, M., Klingebiel, M., Klimach, T., Kohl, R., Krämer, M., Krisna, T., Luebke, A., Mayer, B., Mertes, S., Molleker, S., Petzold, A., Pfeilsticker, K., Port, M., Rapp, M., Reutter, P., Rolf, C., Rose, D., Sauer, D., Schäfler, A., Schlage, R., Schnaiter, M., Schneider, J., Spelten, N., Spichtinger, P., Stock, P., Walser, A., Weigel, R., Weinzierl, B., Wendisch, M., Werner, F., Wernli, H., Wirth, M., Zahn, A., Ziereis, H., and Zöger, M.: ML-CIRRUS - The airborne experiment on natural cirrus and contrail cirrus with the high-altitude long-range research aircraft HALO, B. Am. Meteorol. Soc., 98, 271-288, doi:10.1175/BAMS-D-15-00213.1, 2017.

Wernli, H., Boettcher, M., Joos, H., Miltenberger, A. K., and Spichtinger, P.: A trajectory-based classification of ERA-Interim ice clouds in the region of the North Atlantic storm track, Geophys. Res. Lett., 43, 6657-6664, doi:10.1002/2016GL068922, 2016.

Wirth, M., Fix, A., Mahnke, P., Schwarzer, H., Schrandt, F., and Ehret, G.: The airborne multi-wavelength water vapor differential absorption lidar WALES: System design and performance, Appl. Phys. B, 96, 201-213, doi:10.1007/s00340-009-3365-7, 2009.

Zhang, M. H., Lin, W. Y., Klein, S. A., Bacmeister, J. T., Bony, S., Cederwall, R. T., Del Genio, A. D., Hack, J. J., Loeb, N. G., Lohmann, U., Minnis, P., Musat, I., Pincus, R., Stier, 
P., Suarez, M. J., Webb, M. J., Wu, J. B., Xie, S. C., Yao, M.-S., and Zhang, J. H.: Comparing clouds and their seasonal variations in 10 atmospheric general circulation models with satellite measurements, J. Geophys. Res.-Atmos., 110, D15S02, doi:10.1029/2004JD005021, 2005.
Zhang, Y., Macke, A., and Albers, F.: Effect of crystal size spectrum and crystal shape on stratiform cirrus radiative forcing, Atmos. Res., 52, 59-75, doi:10.1016/S0169-8095(99)00026-5, 1999. 